\title{
Physician compensation structures and how they incentivize specific patient care behaviour
}

\author{
Michael Hewak (Meds 2016), Adam Kovacs-Litman (Meds 2018) \\ Faculty Reviewer: Dr Javeed Sukhera, MD, FRCPC (Department of Psychiatry)
}

\section{INTRODUCTION}

The word "altruism" is commonly ascribed to those who pursue a career in healthcare. However, looking at medicine through the lens of altruism shuts our eyes to the inherent humanity of physicians and limits our ability to provide optimal care. It is unreasonable to expect that physicians will (whether consciously or unconsciously) always prioritize ideal health outcomes in the face of varying incentives. This is especially true given that there is no single universally accepted definition of what "ideal health outcomes" would be. Unsurprisingly, a recent Cochrane review of the subject found that physician compensation models do in fact influence behavior. ${ }^{1}$ How then can we align physician incentives with quality care?

There are four discrete compensation structures in use, with a blend of these commonly employed. Fee-for-service (FFS) models compensate doctors a set amount for each service they perform. Capitation models offer compensation based on the total number of patients under a doctor's care, regardless of how frequently each patient seeks care. Salary models offer physicians fixed remuneration that does not vary based on the services they perform nor patient demographics and are commonly employed by hospitals and community health centers. Pay for performance (P4P) models provide direct financial incentives for meeting certain specific treatment goals. ${ }^{2,3}$

In Canada, $40 \%$ of physicians primarily receive FFS payments ( $>90 \%$ of their income), $10 \%$ primarily receive salaried payments, and $1 \%$ primarily receive capitation compensation. $33 \%$ of physicians receive a blend and about $16 \%$ receive the majority of their compensation through other forms, including $\mathrm{P} 4 \mathrm{P} /$ incentives, short term contracts, and per diems. ${ }^{4}$

\section{HEALTH OUTCOMES}

There are several key health outcomes which are affected directly by physician remuneration schemes. The most significant include quantity of patient visits, quality of patient care, efficiency of resource use, and physician acceptance of complex patients., ${ }^{2,3}$

The effect that a given compensation scheme has on health outcomes is closely correlated with the "variability" in remuneration received, which is a representation of a physician's control over their own income. FFS and P4P schemes are considered widely variable, while salaried systems are considered fixed. Capitation models fall somewhere in between, but generally produce outcomes more in line with salary models. ${ }^{4}$ This establishes a spectrum by which we can compare the different models.

FFS models give physicians considerable control over their earning potential but in so doing create a mixed bag of externalities. It creates an incentive for physicians to provide a higher quantity of treatment to patients, as payment is dependent on the quantity delivered. FFS also incentivizes physicians to perform a high volume of procedures and tests that have greater fees attached to their provision. By extension, FFS unfortunately encourages the provision of unneeded investigations and treatments, undermining the principles of resource management, and potentially biasing physicians in favor of carrying out more expensive actions when a simpler option may suffice. ${ }^{5-7}$

Capitation models are perhaps the best at reinforcing the importance of preventative medicine and resource management. However, this model does not offer additional remuneration for seeing the same patient multiple times, so a physician is unintentionally rewarded for seeing a patient as little as possible. The result is an emphasis on prevention, the conservation of resources and the use of treatment plans that require little management and have fewer side effects and complications. Potential negative consequences include an adverse impact on meaningful doctor-patient relationships, and a decreased incentive to see the same patient multiple times (even when warranted) or accept complex cases. ${ }^{7-13}$

Salary models reimburse physicians independent of the number of patients they see, the amount of time spent with patients, and the type of services provided. Monetary incentives are significantly limited, so there is no financial motivation for a physician to work harder than the minimum or to conserve resources; however, on the positive side this also means there is no financial deterrent to spending more time with patients, taking on difficult patients, or utilizing more intensive and involved treatment regimes.,14

$\mathrm{P} 4 \mathrm{P}$ models seek to correct many of the problems inherent to FFS, capitation, and salary systems. Since 2002, Ontario has gradually introduced more $\mathrm{P} 4 \mathrm{P}$ measures, particularly within the realm of family medicine. Such measures include incentives for providing monitoring tests to diabetics (HbAlc levels, cholesterol levels, and eye tests), administering flu shots to vulnerable populations, and many others. A recent Cochrane review showed that 6 of 7 published studies on the effectiveness of P4P showed clear positive impacts on patient outcomes. ${ }^{15}$ The actual magnitude of these impacts however were somewhat modest, and some research has pointed out that some specific types of P4P (for example those associated with mental health and drug abuse) are in need of optimization before they become cost-effective. ${ }^{16}$ Despite this, the effects when these incentives are fine-tuned and implemented on a broader scale are certainly worth investigating. 


\section{LITERATURE REVIEW}

There are several studies that seek to quantifiably contrast physician compensation models. An analysis of family physician behavior showed that primarily-FFS physicians spent a mean 37 hours seeing approximately 134 patients every week. In comparison, salaried physicians spent only 30 hours seeing 72 patients per week. Physicians compensated through capitation fell between these figures spending 33 hours seeing 96 patients. Thus, the less variable the payment scheme, the fewer hours worked and number of patients seen. ${ }^{18}$

A study by Dumont (2008) showed that although the number of services provided was found to decrease with the rigidity of the payment scheme, the actual amount of time spent performing each service increased, supporting the notion that there may be an inherent balancing of quantity versus quality across payment schemes. ${ }^{17}$ Interestingly, salaried and mixed compensation physicians appeared to use this extra time to pursue teaching or research interests, with a twofold propensity to engage in these activities compared to FFS physicians. ${ }^{14}$

It was found that doctors operating under less variable payment schemes (eg salary) accepted more complex patients, including Aboriginals, low income patients, and those suffering from substance abuse, mental health problems, and/or homelessness. ${ }^{5-11}$ Salaried physicians saw 2-3 times more complex patients on average than FFS physicians, while mixed compensation physicians saw approximately 1.5-2 times more than FFS physicians. ${ }^{17}$

In a general sense, the literature supports the theory that more fixed models of compensation emphasize preventative care, following the logic that healthier patients are seen less often, minimizing work for healthcare providers. Resource efficiency is also significantly improved in more fixed models with fewer unnecessary consults, procedures, and testing. However, more fixed models see a conspicuous decrease in number of patients seen and hours worked as a whole, as the financial incentive to be productive by that measure is no longer present. ${ }^{4}$

\section{CONCLUSION}

With some overlap, each system creates a host of beneficial and deleterious incentives for physician behaviour. The ideal compensation structure would strike a fine balance between these behaviours in optimizing key health outcomes. This ideal model would motivate physicians to see a large enough number of patients to reduce barriers to access, but small enough to ensure each patient receives adequate time and attention. It would ensure doctors do not discriminate against patients for being too complex, and ensure the feasibility of spending lengthy amounts of time with patients who require it. It would also create strong incentives for efficient resource use, limiting the provision of unneeded services.

Since the practice of any two doctors within the same specialty can vary widely, a rigid salary model is not a practical nor equitable choice for the majority of physicians. A salary model is likely only appropriate as a niche form of compensation for certain practice types like emergency physicians, rural doctors with a small patient base, and some academic physicians.
Capitation, although forward-thinking in terms of prioritizing preventative care, encourages a potentially hazardous mindsetundermining the doctor-patient relationship and decreasing the frequency of contact points with the healthcare system. Current data supports the notion that capitation may be better suited playing a role as part of a blended arrangement than as a sole method of remuneration.

In the short period of time $\mathrm{P} 4 \mathrm{P}$ has been in use, it has been utilized largely as an experiment of limited scope, but the results of this experiment are quite promising. ${ }^{18-23}$ More research should be done to determine what services are in need of incentivizing, and what magnitude of incentive motivates behavioral shifts. A harmonized FFS-P4P blend represents a tremendous opportunity to revolutionize medical care. ${ }^{10,24,25}$ Change is always difficult, but such a change would likely be popular for both physicians who would gain increased autonomy and patients who would benefit from improved outcomes. If Ontario could garner enough political capital to embrace such a change in policy, it has the opportunity to become a leader in applying economic principles to the provision of medical services and quality care for patients and families.

\section{REFERENCES}

1. Flodgren G, Eccles MP, Shepperd S. Scott A, Parmelli E, Beyer FR. An overview of reviews evaluating the effectiveness of financial incentives in changing healthcare professional behaviours and patient outcomes. Cochrane Database Syst Rev, 7. Jul 2011.

2. Donaldson C, Gerard KAREN. Paying general practitioners: shedding light on the review of health services. J R Coll Gen Pract. 1989 Mar;39(320):114-7.

3. Leger PT. Physician payment mechanisms. Financing health care: new ideas for a changing society. 2008 Mar;149-76.

4. Blomqvist $\AA$, Busby C. How to pay family doctors: why "pay per patient" is better than fee for service. CD Howe Institute. Oct 2012.

5. Hickson GB, Altemeier WA, Perrin JM. Physician reimbursement by salary or fee-for-service: effect on physician practice behavior in a randomized prospective study. Pediatrics. 1987 Dec;80(3):344-50.

6. Hillman AL, Pauly MV, Kerstein JJ. How do financial incentives affect physicians' clinical decisions and the financial performance of health maintenance organizations? N Engl J Med. 1989 Jul;321(2):86-92.

7. Hutchison B, Birch S, Hurley J, Lomas J, Stratford-Devai F. Do physician-payment mechanisms affect hospital utilization? A study of health service organizations in Ontario. CMAJ. 1996 Mar;154(5):653.

8. Balkrishnan R, Hall MA, Mehrabi D, Chen GJ, Feldman SR, Fleischer Jr AB. Capitation payment, length of visit, and preventive services: evidence from a national sample of outpatient physicians. Am J Manag Care. 2002 Apr;8(4):332-40.

9. Catalano R, Libby A, Snowden L, Cuellar AE. The effect of capitated financing on mental health services for children and youth: the Colorado experience. Am J Public Health. 2000 Dec;90(12):1861.

10. Chaix-Couturier C, Durand-Zaleski I, Jolly D, Durieux P. Effects of financial incentives on medical practice: results from a systematic review of the literature and methodological issues. Int J Qual Health Care. 2000 Apr;12(2):133-42.

11. Ellis RP. Creaming, skimping and dumping: provider competition on the intensive and extensive margins. J Health Econ. 1998 Oct;17(5):53755. 
12. Iversen T, Lurås $H$. The effect of capitation on GPs' referral decisions. Health Econ. 2000 Apr;9(3):199-210.

13. Rice N, Smith PC. Capitation and risk adjustment in health care financing: an international progress report. Milbank Q. 2001 Dec;79(1):81-113.

14. Gosden T, Sibbald B, Williams J, Petchey R, Leese B. Paying doctors by salary: a controlled study of general practitioner behaviour in England. Health Policy. 2003 Jun;64(3):415-23.

15. Scott A, Sivey P, Ait Ouakrim D, Willenberg L, Naccarella L, Furler J, Young, D. The effect of financial incentives on the quality of health care provided by primary care physicians. Cochrane Database Syst Rev. 2011 Sep;9(9).

16. Bremer R, Scholle SH, Keyser D, Houtsinger JK, Pincus HA. Pay for performance in behavioral health. Psychiatr Serv. 2008 Dec;59(12):1419-29.

17. Devlin RA, Sarma S. Do physician remuneration schemes matter? The case of Canadian family physicians. J Health Econ. 2008 Sep;27(5):1168-81.

18. Dumont E, Fortin B, Jacquemet N, \& Shearer B. Physicians' multitasking and incentives: empirical evidence from a natural experiment. $\mathrm{J}$ Health Econ. 2008 27(6):1436-50.

19. Christianson JB, Leatherman S, Sutherland K. Lessons from evaluations of purchaser pay-for-performance programs a review of the evidence. Med Care Res Rev. 2008 Dec;65(6 suppl):5S-35S.
20. Doran T, Fullwood C, Gravelle H, Reeves D, Kontopantelis E, Hiroeh $\mathrm{U}$, Roland M. Pay-for-performance programs in family practices in the United Kingdom. N Engl J Med. 2006 Jul;355(4):375-84.

21. Feasby TF, Gerdes C. Pay-for-performance-can it work in Canada? Healthc Pap. 2005 May;6(4):47-50.

22. Grossbart SR. What's the return? Assessing the effect of "pay-for-performance" initiatives on the quality of care delivery. Med Care Res Rev. $2006 \mathrm{Feb} ; 63$ (1 suppl):29S-48S

23. Kahn CN, Ault T, Isenstein H, Potetz L, Van Gelder S. Snapshot of hospital quality reporting and pay-for-performance under Medicare Health Affairs. Health Aff. 2006 Jan;25(1):148-62.

24. Rosenthal MB, Frank RG, Li Z, Epstein AM. Early experience with pay-for-performance: from concept to practice. JAMA. 2005 Oct;294(14):1788-93.

25. Gosden T, Forland F, Kristiansen IS, Sutton M, Leese B, Giuffrida A, Pedersen, L. Impact of payment method on behaviour of primary care physicians: a systematic review. J Health Serv Res Policy. 2001 Jan;6(1):44-55.

26. Robinson JC. Theory and practice in the design of physician payment incentives. Milbank Q. 2001 Dec;79(2):149-77.

\section{Bluewater Health Sarnia \& Petrolia, Ontario}

Bluewater Health is recruiting for the following positions to provide services to the residents of Sarnia-Lambton both in the community and at the hospital.

- Paediatrician

- Hospitalists

- Internists with special interest in Cardiology \& Rheumatology
- Neurologist

- Psychiatrist

- Emergency Physicians

- Family Physicians (Petrolia) - including low acuity Emergency

Bluewater Health is a 320 bed hospital operating on 2 sites which includes a recently completed $\$ 319$ million redevelopment. The hospital offers excellent medical and diagnostic supports:

- A broad range of diagnostic services, including CT and MRI.

- Full spectrum of specialists available 24/7 (neurosurgery not available)

Situated on the shores of Lake Huron at the border to Michigan, Sarnia offers excellent quality of life, sports, arts and culture, education, state of the art health care, and beautiful natural environment.

To inquire about these positions, please contact:

Dr. Mark Taylor, Chief of Professional Staff

Bluewater Health

Medical affairs@bluewaterhealth.ca

519-464-4400 ext 4534.

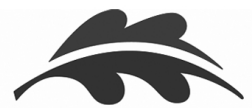

BLUEWATER

H E A L T H

Life, health and renewal. 